\title{
The prognostic implications of growth-related gene product $\beta$ in laryngeal squamous cell carcinoma
}

\author{
MINGMING TANG ${ }^{1}$, XINJIANG XU $^{1}$, JUANJUAN CHEN $^{2}$, JIANGFEI HUANG $^{3}$, BIN JIANG $^{1}$ and LIANG HAN ${ }^{1}$ \\ Departments of ${ }^{1}$ Head and Neck Surgery, and ${ }^{2}$ Medicine, Nantong University Affiliated Tumor Hospital, Nantong, \\ Jiangsu 226361; ${ }^{3}$ Department of Clinical Pathology, Nantong University Affiliated Hospital, \\ Nantong, Jiangsu 226001, P.R. China
}

Received September 16, 2015; Accepted February 13, 2017

DOI: $10.3892 / \mathrm{ol} .2017 .6604$

\begin{abstract}
Growth-related gene product $\beta(\mathrm{GRO} \beta)$ is an angiogenic chemokine that belongs to the $\mathrm{CXC}$ chemokine family, and a number of studies have suggested that GRO $\beta$ is associated with tumor development and progression. However, a number of studies have investigated the association between GRO $\beta$ expression and the clinical attributes of laryngeal squamous cell carcinoma (LSCC). In the present study, one-step quantitative polymerase chain reaction and immunohistochemistry analysis were used to detect GRO $\beta$ expression and evaluate the association between its expression and the clinicopathological characteristics of LSCC. The results demonstrated that the GRO $\beta$ mRNA and protein expression levels were significantly increased in LSCC compared with the corresponding non-cancerous tissues. GRO $\beta$ protein expression in LSCC was associated with tumor-node-metastasis stage, lymph node metastasis and histopathological grade. The Kaplan-Meier method and Cox multi-factor analysis indicated that high GRO $\beta$ expression, lymph node metastasis and histopathological grade were significantly associated with poor survival of patients with LSCC. These data indicated that GRO $\beta$ may be a novel prognostic biomarker of LSCC.
\end{abstract}

\section{Introduction}

Laryngeal cancer, which is a common type of head and neck malignancy, is the 11th most common neoplasm in males (1). Laryngeal squamous cell carcinomas (LSCC) account for $>95 \%$ of laryngeal cancers, and LSCC accounts for $25 \%$ of all types of head and neck cancers (2). In the last decade, the incidence rate of LSCC has increased, with invasion and metastasis being

Correspondence to: Dr Liang Han, Department of Head and Neck Surgery, Nantong University Affiliated Tumor Hospital, 30 Tongyang North Road, Tongzhou, Nantong, Jiangsu 226361, P.R. China

E-mail: h161697@126.com

Key words: growth-related gene product $\beta$, laryngeal squamous cell carcinoma, quantitative polymerase chain reaction, immunohistochemistry, prognosis the primary factors that affect the prognosis of patients, with a 5-year survival rate of $\sim 60 \%(3,4)$. At present, laryngectomy is the major effective treatment strategy used for LSCC (5). In addition, larynx-preservation protocols using chemotherapy or radiotherapy are also developing (6). However, the aforementioned treatments often do not achieve a satisfactory clinical outcome and the overall survival of LSCC has not improved for years (7). There is a lack of sensitive and specific biomarkers to identify LSCC characteristics and to predict LSCC outcomes.

Growth-related gene product $\beta(\mathrm{GRO} \beta)$ is an angiogenic chemokine belonging to the CXC chemokine family, and growing evidence has indicated that chemokines are associated with tumor development and progression $(8,9)$. GRO $\beta$ was initially identified in melanoma cell lines, and high expression of GRO $\beta$ was observed in human melanomas (10). Several previous studies have reported the involvement of GRO $\beta$ in tumorigenesis $(11,12)$. GRO $\beta$ also attracted tumor cells and contributed to esophageal cancer cell transformation and growth (13). Blocking GRO $\beta$ expression resulted in reduced proliferation and colonization capacity of esophageal cancer cells (14). Upregulation of GRO $\beta$-chemokine receptor 2 (CXCR2) signaling significantly increased the proliferation of cancer cells by modulating epithelial growth factor-1 (EGR-1) via extracellular signal-regulated kinase 1/2 (ERK1/2) (15). Previous studies have detected differentiated expression of GRO $\beta$, and high GRO $\beta$ expression was associated with several malignant features of colorectal cancer, hepatocellular carcinoma and esophageal cancer (16-18). However, although GRO $\beta$ exhibits oncogenic functions, the association between GRO $\beta$ expression and LSCC characteristics remains to be fully determined. Additional studies are required to determine whether GRO $\beta$ may serve as a biomarker for LSCC.

In the present study, the expression of GRO $\beta$ in LSCC tissue was detected via one-step quantitative reverse-transcription polymerase chain reaction (RT-qPCR) and immunohistochemistry (IHC). The associations between GRO $\beta$ expression and clinicopathological attributes of LSCC, in particular the prognostic status, were investigated.

\section{Materials and methods}

Patient specimens. A total of 20 samples of fresh LSCC tissues and corresponding non-cancerous tissues were collected 
from the Department of Pathology, the Affiliated Hospital of Nantong University (Nantong, China) between January 2013 and December 2014. All of the 20 samples were obtained from males (range, 48-70 years; average age, 60.30 5 .42 years). Simultaneously, a total of 126 paraffin-embedded LSCC tissue samples (124 males and 2 females; range, $42-87$ years; average age, $64.10 \pm 8.59$ years) and 28 matched adjacent paracancerous tissue $(<1 \mathrm{~cm})$ samples obtained from males (range, 52-76 years; average age, $62.93 \pm 5.80$ years), were collected from the archives of the Department of Pathology, the Affiliated Hospital of Nantong University, between January 2002 and December 2012. Diagnosis of LSCC was confirmed according to the latest World Health Organization criteria and tumor-node-metastasis (TNM) stage classification $(19,20)$. The original clinical data were obtained from hospital medical records, and include details pertaining to patient sex and age, tobacco use, alcohol consumption, TNM stage, lymph node metastasis status and histopathological grade. None of the patients received radiotherapy or chemotherapy prior to surgery. Written informed consent was acquired from each patient enrolled in the present study. Ethical approval to perform the present study was granted by the Human Research Ethics Committee of the Affiliated Hospital of Nantong University.

One-step RT-qPCR. A total of 20 fresh LSCC tissue samples and corresponding non-cancerous tissue samples were used to perform one-step qPCR. Total RNA was extracted using TRIzol reagent (Invitrogen; Thermo Fisher Scientific, Inc., Waltham, MA, USA). Expression levels of GRO $\beta$ and glyceraldehyde 3-phosphate dehydrogenase (GAPDH) were determined by RT-qPCR using the $\mathrm{iQ5}$ detection system (Bio-Rad Laboratories, Inc., Hercules, CA, USA) and the SensiMix One-Step SYBR-Green kit (Quantace Ltd., London, UK). The primers used were as follows: GRO $\beta$ forward, 5'-CAC CAA CCA CCA GGC TAC-3' and reverse, 5'-CTT CAG GGT CAA GGC AAA-3'; and GAPDH forward, 5'-TAT TAC CTG GAC GAG ATT CCCC-3' and reverse, 5'-TAT TAC CTG GAC GAG ATT CCCC-3'. Amplification conditions were as described in previous studies (21-23). GAPDH was used as the reference gene to normalize the $\mathrm{Cq}$ values of cancer and control tissue samples. The calculation formula of all sample is $2^{-\Delta \Delta \mathrm{Cq}}(24)$. Each experiment was repeated 3 times.

Tissue microarray (TMA) construction and IHC. A total of 126 LSCC tissues were prepared and TMAs were produced by Xinchao Biotech Co. Ltd. (Shanghai, China) to proceed IHC analysis. Core tissue biopsies (diameter, $2 \mathrm{~mm}$ ) were taken from individual paraffin-embedded sections and arranged in the new paraffin blocks. The tissue microarray was cut into $4 \mu \mathrm{m}$ sections and placed on microscope slides. IHC was performed as described previously $(25,26)$. Briefly, TMA sections were incubated with a primary polyclonal anti-GRO $\beta$ antibody (1:200; cat. no. ab10366; Abcam, Cambridge, UK) diluted in PBS at $4^{\circ} \mathrm{C}$ for $8 \mathrm{~h}$. Following washing with PBS at $37^{\circ} \mathrm{C}$ for $30 \mathrm{~min}$, sections were incubated with horseradish peroxidase-conjugated secondary antibody (1:2,000; cat. no. P0160; Dako; Agilent Technologies, Inc., Santa Clara, CA, USA). Negative control reactions used PBS instead of the primary antibody. The results of IHC were evaluated by a double-blind method whereby the staining results were determined under a

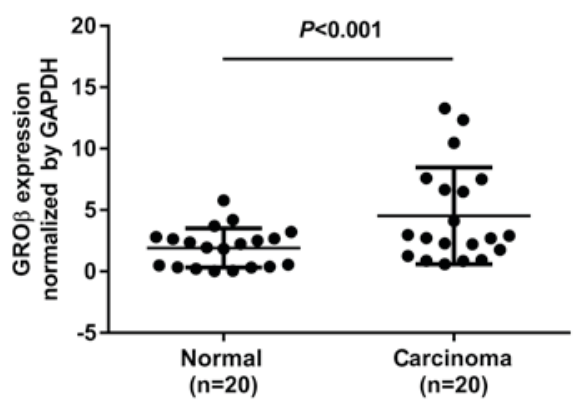

Figure 1. GRO $\beta$ mRNA levels in LSCC tissues were significantly increased compared with corresponding non-cancerous tissues, as determined by reverse transcription-quantitative polymerase chain reaction, with data normalized to GAPDH mRNA levels $(\mathrm{P}=0.009)$. GRO $\beta$, growth-related gene product $\beta$; LSCC, laryngeal squamous cell carcinoma; GADPH, glyceraldehyde 3-phosphate dehydrogenase.

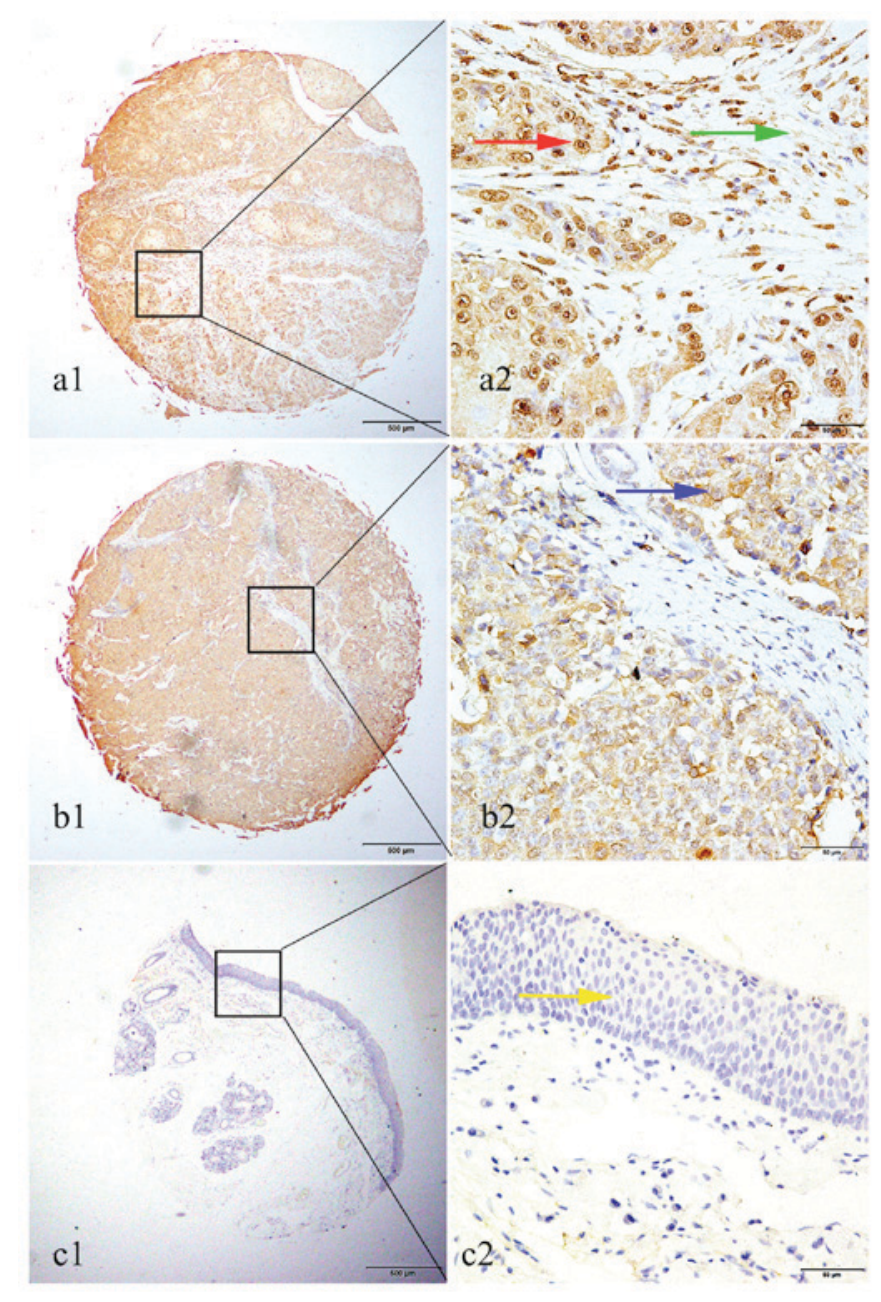

Figure 2. Representative pattern of GRO $\beta$ protein expression in LSCC samples and corresponding non-cancerous tissue samples. (A1) Strong nuclear staining of GRO $\beta$ in an LSCC tissue sample (original magnification, $x 40$ ). (A2) Red arrow indicates positive staining in the nucleus of cancer cells. Green arrow indicates positive staining in the stroma of cancer cells (magnification, $x 400$ ). (B1) Strong cytoplasmic staining of GRO $\beta$ in an LSCC tissue sample (original magnification, $x 40$ ). (B2) Blue arrow indicates positive staining in the cytoplasm of cancer cells (magnification, $\mathrm{x} 400$ ). (C1) Negative staining of GRO $\beta$ in a corresponding non-cancerous tissue sample (original magnification, $x 40)$. (C2) Yellow arrow indicates negative staining in the epithelial cells (magnification, $\mathrm{x} 400$ ). GRO $\beta$, growth-related gene product $\beta$; LSCC, laryngeal squamous cell carcinoma. 
Table I. Association of GRO $\beta$ expression with clinical attributes of laryngeal squamous cell carcinoma.

\begin{tabular}{|c|c|c|c|c|c|}
\hline \multirow[b]{2}{*}{ Groups } & \multirow[b]{2}{*}{$\mathrm{n}$} & \multicolumn{2}{|c|}{ GRO $\beta$ expression, $\mathrm{n}$} & \multirow[b]{2}{*}{$\chi^{2}$} & \multirow[b]{2}{*}{ P-value } \\
\hline & & High expression & Low expression & & \\
\hline Total & 126 & 72 & 54 & & \\
\hline \multicolumn{6}{|l|}{ Age } \\
\hline$\leq 60$ years & 41 & 23 & 18 & 0.027 & 0.869 \\
\hline$>60$ years & 85 & 49 & 36 & & \\
\hline \multicolumn{6}{|c|}{ Tobacco consumption } \\
\hline Yes & 68 & 41 & 27 & 0.261 & 0.609 \\
\hline No & 31 & 17 & 14 & & \\
\hline Unknown & 27 & 14 & 13 & & \\
\hline \multicolumn{6}{|c|}{ Alcohol consumption } \\
\hline Yes & 48 & 31 & 17 & 1.381 & 0.240 \\
\hline No & 51 & 27 & 24 & & \\
\hline Unknown & 27 & 14 & 13 & & \\
\hline \multicolumn{6}{|l|}{ TNM stage } \\
\hline Stage I, II & 65 & 31 & 33 & 4.383 & 0.036 \\
\hline Stage III, IV & 49 & 34 & 16 & & \\
\hline Unknown & 12 & 7 & 5 & & \\
\hline \multicolumn{6}{|c|}{ Lymph node metastasis } \\
\hline Yes & 18 & 15 & 3 & 5.667 & 0.017 \\
\hline No & 105 & 56 & 49 & & \\
\hline Unknown & 3 & 1 & 2 & & \\
\hline \multicolumn{6}{|c|}{ Histopathological grade } \\
\hline High & 11 & 9 & 0 & 9.861 & 0.007 \\
\hline Moderate & 65 & 37 & 28 & & \\
\hline Low & 47 & 26 & 21 & & \\
\hline Unknown & 3 & 0 & 5 & & \\
\hline
\end{tabular}

GRO $\beta$, growth-related gene product $\beta$; TNM, tumor-node-metastasis.

light optical microscope at magnifications $x 40$ and x400, by two independent pathologists.

Expression levels of GRO $\beta$ protein were evaluated by observing the staining density and intensity of positive cells as described previously $(27,28)$. Staining density of positive cells was scored as follows: 0 , negative; $1,1-10 \%$ positive cells; $2,10-50 \%$ positive cells, and $3,>50 \%$ positive cells. Similarly, staining intensity was scored as: 0 , no color; 1 , yellow for weak positive; 2 , light brown for medium positive and 3 , brown for strong positive. The two components were produced to obtain an overall expression score, as follows: $0,(-) ; 1-3,(+) ; 4-6,(++)$; and $7-9,(+++)$. The degree of GRO $\beta$ staining was quantified using a two-level grading system, and staining scores were defined as follows: $\leq 3$, low expression and 4-9, high expression.

Statistical analysis. The GRO $\beta$ mRNA expression in fresh LSCC tissues compared with corresponding non-cancerous tissues was analyzed with the Wilcoxon signed-rank nonparametric test. The association of GRO $\beta$ expression on clinicopathological items of LSCC was calculated by the $\chi^{2}$ test. Univariate and multivariate analyses were performed using Cox proportional hazards regression models to explore the prognostic factors. The Kaplan-Meier method was utilized to evaluate the association between GRO $\beta$ expression and LSCC outcomes. For all tests, $\mathrm{P}<0.05$ was considered to indicate a statistically significant difference. All the statistical analyses were conducted using uSTATA (version 12.0; StataCorp LLC, College Station, TX, USA) and SPSS 18.0 statistical software (SPSS, Inc., Chicago, IL, USA).

\section{Results}

Detection of GRO $\beta$ mRNA expression in LSCC by RT-qPCR. When normalized to GAPDH, the means of $G R O \beta$ mRNA in LSCC and corresponding non-cancerous tissues were $4.53 \pm 0.882$ and $1.91 \pm 0.358$, respectively $(\mathrm{t}=2.746 ; \mathrm{P}=0.009$; Fig. 1). GRO $\beta$ expression averaged 2.41-fold higher in the LSCC samples compared with the non-cancerous tissues (Fig. 1).

Detection of GRO $\beta$ protein expression in LSCC by IHC. High GRO $\beta$ expression was detected in 72 of $126(57.1 \%)$ LSCC tissues, while only 2 cases of 28 non-cancerous tissues $(7.1 \%)$ exhibited high GRO $\beta$ expression. There was a significant difference in high expression rate 
Table II. Univariate and multivariate analysis of prognostic factors in laryngeal squamous cell carcinoma for overall survival time.

\begin{tabular}{|c|c|c|c|c|}
\hline & \multicolumn{2}{|c|}{ Univariate analysis } & \multicolumn{2}{|c|}{ Multivariate analysis } \\
\hline & P-value & $95 \% \mathrm{CI}$ & P-value & $95 \% \mathrm{CI}$ \\
\hline \multicolumn{5}{|l|}{ GRO $\beta$ expression } \\
\hline High vs. low & 0.004 & $1.411-6.249$ & 0.043 & $1.025-5.164$ \\
\hline \multicolumn{5}{|l|}{ Age } \\
\hline$\leq 60$ vs. $>60$ years & 0.197 & & 0.125 & \\
\hline \multicolumn{5}{|l|}{ Tobacco consumption } \\
\hline Yes vs. no & 0.210 & & 0.398 & \\
\hline \multicolumn{5}{|l|}{ Alcohol consumption } \\
\hline Yes vs. no & 0.595 & & 0.226 & \\
\hline \multicolumn{5}{|l|}{ TNM stage } \\
\hline Stage I, II vs. Stage III, IV & 0.002 & $1.409-5.046$ & 0.226 & $0.774-3.633$ \\
\hline \multicolumn{5}{|l|}{ Lymph node metastasis } \\
\hline Yes vs. no & 0.001 & $2.122-8.706$ & 0.007 & $1.418-9.339$ \\
\hline \multicolumn{5}{|l|}{ Histopathological grade } \\
\hline High vs. moderate vs. low & 0.017 & $1.112-2.971$ & 0.038 & $1.031-3.073$ \\
\hline
\end{tabular}

GRO $\beta$, growth-related gene product $\beta$; TNM, tumor-node-metastasis; CI, confidence interval.

A

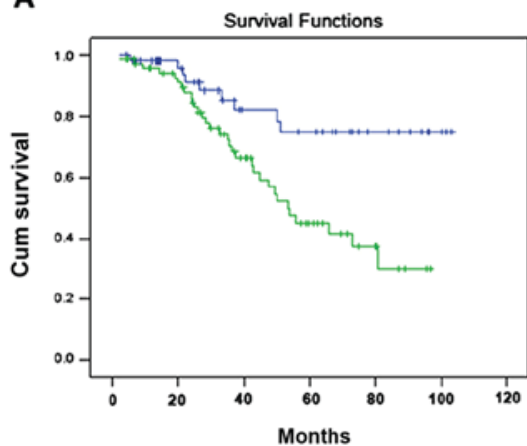

C

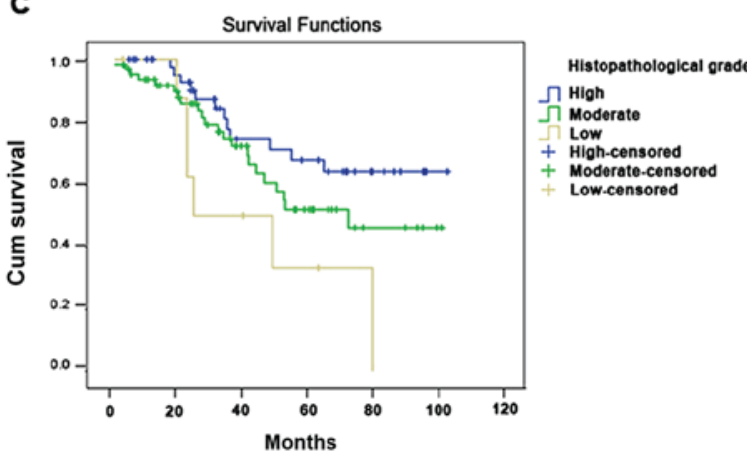

B
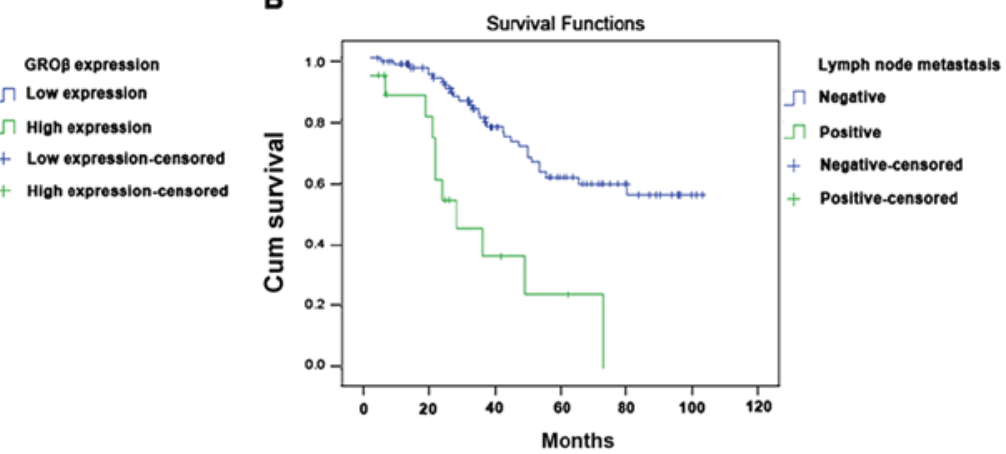

Figure 3. Survival analysis of patients with laryngeal squamous cell carcinoma using the Kaplan-Meier method. (A) Overall survival rate in patients with high GRO $\beta$ expression (green line) was significantly lower compared with patients with low GRO $\beta$ expression (blue line). (B) Overall survival rate in patients with positive lymph node metastasis (green line) was significantly lower compared with patients with negative lymph node metastasis (blue line). (C) Overall survival rate in patients with low histopathological grade (yellow line) was significantly lower compared with patients with moderate and high histopathological grade (green and blue line, respectively). GRO $\beta$, growth-related gene product $\beta$; Cum, cumulative.

of GRO $\beta$ between LSCC tissues and non-cancerous tissues $(\mathrm{P}<0.001)$. Positive staining of GRO $\beta$ was mainly localized in the nucleus of cancer cells (Fig. 2).
Although positive cytoplasmic and stromal staining of GRO $\beta$ was observed in certain cases, the case number was too small to perform statistics (Fig. 2). 
Association between GRO $\beta$ expression and clinical attributes. The associations between GRO $\beta$ protein expression and the clinical characteristics of patients with LSCC are listed in Table I. Elevated GRO $\beta$ expression was significantly associated with TNM stage $(\mathrm{P}=0.036)$, lymph node metastasis $(\mathrm{P}=0.017)$ and histopathological grade $(\mathrm{P}=0.007)$. By contrast, no association was detected between GRO $\beta$ expression and other clinical characteristics, including age, tobacco or alcohol consumption (Table I).

Survival analysis. Univariate analysis revealed that the overall survival of patients with LSCC was associated with high GRO $\beta$ expression $(\mathrm{P}=0.004)$, TNM stage $(\mathrm{P}=0.002)$, lymph node metastasis $(\mathrm{P}=0.001)$ and histopathological grade $(\mathrm{P}=0.017)$. Multivariate analysis identified that high GRO $\beta$ expression $(\mathrm{P}=0.048)$, lymph node metastasis $(\mathrm{P}=0.007)$ and histopathological grade $(\mathrm{P}=0.038)$ were independent prognostic factors for overall survival (Table II). Furthermore, Kaplan-Meier survival curves indicated that patients with LSCC with low GRO $\beta$ expression, negative lymph node metastasis and high histopathological grade had a significantly longer overall survival time (Fig. 3).

\section{Discussion}

Chemokines are a superfamily of small, cytokine-like proteins that interact with cell-surface receptors during development of the host immune response $(29,30)$. Previous data have revealed that chemokines are involved in human cancer, in addition to their functions in development and inflammatory responses (31). GRO is a member of the CXC chemokine family, which is composed of GRO $\alpha, \operatorname{GRO} \beta$ and $\mathrm{GRO} \gamma$ (32). GRO $\alpha$ is expressed at high levels in a variety of tumors and is associated with tumor proliferation, angiogenesis and metastasis $(33,34)$. A previous study also confirmed that high GRO $\alpha$ expression is associated with an aggressive malignant phenotype of LSCC, and GRO $\alpha$ may be a valuable prognostic biomarker for patients with LSCC (35). Several studies have explored the involvement of GRO $\beta$ in tumor formation and development. For example, Wang et al (15) and Dong et al (18) reported that GRO $\beta$ is highly expressed in esophageal squamous cell carcinoma. Doll et al (36) also reported a significantly elevated level of GRO $\beta$ expression in colon carcinoma compared with normal tissue. GRO $\beta$ may form an autocrine loop by binding its receptor CXCR2 and activating the Ras-ERK1/2 signaling pathway, which is important for cell proliferation (15). This pathway in turn enhances the transcription and expression of EGR-1, a transcription factor that regulates the expression of downstream factors associated with cell growth and cell cycle regulation, thereby promoting tumor progression (37). Based on this information, although the exact function of GRO $\beta$ in LSCC remains to be investigated, it is reasonable to speculate that the GRO $\beta / C X C R 2$ axis is involved in LSCC development. In the present study, the clinicopathological significance of GRO $\beta$ in LSCC was detected with a particular focus on its prognostic characteristics.

The results of RT-qPCR demonstrated that GRO $\beta$ mRNA levels were increased in LSCC compared with non-cancerous tissues. This data was consistent with that reported in a series of previous studies, in which the expression of GRO $\beta$ was revealed to be significantly elevated in cancer tissues compared with normal tissues $(15,18,36)$. The expression of GRO $\beta$ was confirmed by conducting IHC. Consistent with the results of RT-qPCR, the IHC results revealed increased GRO $\beta$ expression in LSCC tissues compared with non-cancerous tissues. The IHC staining pattern revealed that GRO $\beta$ protein was mainly localized in the nucleus of LSCC cells. In addition, small LSCC cases exhibited positive cytoplasmic and stromal staining of GRO $\beta$. However, Ye et al (38) reported that GRO $\beta$ was principally detected in the cytoplasm in ovarian cancer, and it was presumed that the reason for the differential distribution of GRO $\beta$ may be due to the differences in cancer type, antibody used and experimental protocol. Additional studies that enroll a larger number of clinical samples of LSCC in particular cancer categories are necessary to validate the findings of the present study.

GRO $\beta$ overexpression (including in serum, plasma and tissue) has been reported to be associated with several malignant features of human cancers $(36,37)$. In the present study, high GRO $\beta$ expression in LSCC was associated with three clinical pathological characteristics, namely TNM stage, lymph node metastasis and histopathological grade. In addition, univariate and multivariate analysis revealed the prognostic value of GRO $\beta$ overexpression, indicating that patients with LSCC with high GRO $\beta$ expression may have poor prognoses. The Kaplan-Meier curve also implied that high GRO $\beta$ expression in patients with LSCC indicated unfavorable overall survival. The obtained data were consistent with the results of a previous study, which illustrated that high GRO $\beta$ expression was associated with poor prognosis and contributed to ovarian cancer tumorigenesis and metastasis (38).

In conclusion, to the best of our knowledge, the present study was the first to examine GRO $\beta$ mRNA expression with RT-qPCR and protein expression with IHC in LSCC. The results revealed that high GRO $\beta$ expression may be associated with the development and progression of LSCC. Therefore, GRO $\beta$ may be a useful biomarker for predicting the prognosis of LSCC, and targeting GRO $\beta$ may provide a novel strategy for LSCC treatment.

\section{Acknowledgements}

The present study was supported by grants from the Science and Technique Development Fund (grant no. 20120066) of Nantong, Jiangsu, China and Youth Medical Personnel of Scientific Research Fund (grant no. WQ2016066) of Nantong Municipal Commission of Health, and Family Planning and Nantong Tumor Hospital (Nantong, China).

\section{References}

1. Shen Z, Li Q, Deng H, Lu D, Song H and Guo J: Long non-coding RNA profiling in laryngeal squamous cell carcinoma and its clinical significance: Potential biomarkers for LSCC. PLoS One 9: e108237, 2014.

2. Almadori G, Bussu F, Cadoni G, Galli J, Paludetti G and Maurizi M: Molecular markers in laryngeal squamous cell carcinoma: Towards an integrated clinicobiological approach. Eur J Cancer 41: 683-693, 2005. 
3. Liu Y, Su Z, Li G, Yu C, Ren S, Huang D, Fan S, Tian Y, Zhang X and Qiu Y: Increased expression of metadherin protein predicts worse disease-free and overall survival in laryngeal squamous cell carcinoma. Int J Cancer 133: 671-679, 2013.

4. Ma J, Wang J, Fan W, Pu X, Zhang D, Fan C, Xiong L, Zhu H, Xu N Chen R and Liu S: Upregulated TIMP-1 correlates with poor prognosis of laryngeal squamous cell carcinoma. Int J Clin Exp Pathol 7: 246-254, 2013.

5. Rodrigo JP, Coca-Pelaz A and Suárez C: The current role of partial surgery as a strategy for functional preservation in laryngeal carcinoma. Acta Otorrinolaringol Esp 62: 231-238, 2011 (In Spanish).

6. Ajithkumar T, Price S, Horan G, Burke A and Jefferies S: Prevention of radiotherapy-induced neurocognitive dysfunction in survivors of paediatric brain tumours: The potential role of modern imaging and radiotherapy techniques. Lancet Oncol 18: e91-e100, 2017.

7. Mountzios G, Kostopoulos I, Kotoula V, Sfakianaki I, Fountzilas E, Markou K, Karasmanis I, Leva S, Angouridakis N, Vlachtsis K, et al: Insulin-like growth factor 1 receptor (IGF1R) expression and survival in operable squamous-cell laryngeal cancer. PLoS One 8: e54048, 2013.

8. Messina JL, Fenstermacher DA, Eschrich S, Qu X, Berglund AE, Lloyd MC, Schell MJ, Sondak VK, Weber JS and Mulé JJ: 12-Chemokine gene signature identifies lymph node-like structure in melanoma: Potential for patient selection for immunotherapy? Sci Rep 2: 765, 2012.

9. Mitkin NA, Hook CD, Schwartz AM, Biswas S, Kochetkov DV, Muratova AM, Afanasyeva MA, Kravchenko JE, Bhattacharyya A and Kuprash DV: p53-dependent expression of CXCR5 chemokine receptor in MCF-7 breast cancer cells. Sci Rep 5: 9330, 2015.

10. Richmond A and Thomas HG: Melanoma growth stimulatory activity: Isolation from human melanoma tumors and characterization of tissue distribution. J Cell Biochem 36: 185-198, 1988.

11. Zhao H, Zhu H, Jin Q, Zhang S, Wang W, Wang D and Huang J: Association of high expression of Gro $\beta$ with clinical and pathological characteristics of unfavorable prognosis in gastrointestinal stromal tumors. Dis Markers 2015: 171035, 2015.

12. Zheng Z, Zheng M, Bi J, Feng Q, Yue Z, Zhou Y, Hu W, Zhang H and Gao H: Serum GRO $\beta$ : A potential tumor-associated biomarker for colorectal cancer. Int J Clin Exp Med 8: 2526-2535, 2015.

13. Dong QM, Zhang JQ, Li Q, Bracher JC, Hendricks DT and Zhao XH: Clinical significance of serum expression of GRO $\beta$ in esophageal squamous cell carcinoma. World J Gastroenterol 17: 2658-2662, 2011.

14. Bruyère C, Lonez C, Duray A, Cludts S, Ruysschaert JM, Saussez S, Yeaton P, Kiss R and Mijatovic T: Considering temozolomide as a novel potential treatment for esophageal cancer. Cancer 117: 2004-2016, 2011

15. Wang B, Hendricks DT, Wamunyokoli F and Parker MI: A growth-related oncogene/CXC chemokine receptor 2 autocrine loop contributes to cellular proliferation in esophageal cancer. Cancer Res 66: 3071-3077, 2006.

16. Zheng Z, Zheng M, Bi J, Feng Q, Yue Z, Zhou Y, Hu W, Zhang H and Gao H: Serum GROß: A potential tumor-associated biomarker for colorectal cancer. Int J Clin Exp Med 8: 2526-2535, 2015.

17. Li Y, Wang Y and Zhang P: Clinical significance of serum expression of GRO $\beta$ in hepatocellular carcinoma. Tumour Biol 36: 6445-6449, 2015.

18. Dong QM, Zhang JQ, Li Q, Bracher JC, Hendricks DT and Zhao XH Clinical significance of serum expression of GRO $\beta$ in esophageal squamous cell carcinoma. World J Gastroenterol 17: 2658-2662, 2011.

19. Thompson L: World Health Organization classification of tumours: Pathology and genetics of head and neck tumours. Ear Nose Throat J 85: 74, 2006.

20. Webber C, Gospodarowicz M, Sobin LH, Wittekind C, Greene FL, Mason MD, Compton C, Brierley J and Groome PA: Improving the TNM classification: Findings from a 10-year continuous literature review. Int J Cancer 135: 371-378, 2014
21. Huang J, Fan X, Wang X, Lu Y, Zhu H, Wang W, Zhang S and Wang Z: High ROR2 expression in tumor cells and stroma is correlated with poor prognosis in pancreatic ductal adenocarcinoma. Sci Rep 5: 12991, 2015

22. Xu Y, Wang C, Zhang Y, Jia L and Huang J: Overexpression of MAGE-A9 Is predictive of poor prognosis in epithelial ovarian cancer. Sci Rep 5: 12104, 2015.

23. Chen R, Lu M, Wang J, Zhang D, Lin H, Zhu H, Zhang W, Xiong L, Ma J, Mao Y, et al: Increased expression of Trop2 correlates with poor survival in extranodal NK/T cell lymphoma, nasal type. Virchows Arch 463: 713-719, 2013

24. Livak KJ and Schmittgen TD: Analysis of relative gene expression data using real-time quantitative PCR and the 2(-Delta Delta C(T)) Method. Methods 25: 402-408, 2001.

25. Han L, Jiang B, Wu H, Wang X, Tang X, Huang J and Zhu J: High expression of CXCR2 is associated with tumorigenesis, progression and prognosis of laryngeal squamous cell carcinoma. Med Oncol 29: 2466-2472, 2012

26. Zhu H, Lu J, Wang X, Zhang H, Tang X, Zhu J and Mao Y: Upregulated ZO-1 correlates with favorable survival of gastrointestinal stromal tumor. Med Oncol 30: 631, 2013.

27. Welsh JB, Sapinoso LM, Kern SG, Brown DA, Liu T, Bauskin AR, Ward RL, Hawkins NJ, Quinn DI, Russell PJ, et al: Large-scale delineation of secreted protein biomarkers overexpressed in cancer tissue and serum. Proc Natl Acad Sci USA 100: 3410-3415, 2003.

28. Han L, Jiang B, Wu H, Zhang S and Lu X: Expression and prognostic value of MAGE-A9 in laryngeal squamous cell carcinoma. Int J Clin Exp Pathol 7: 6734-6742, 2014

29. Charo IF and Ransohoff RM: The many roles of chemokines and chemokine receptors in inflammation. N Engl J Med 354: 610-621, 2006.

30. Ebnet K and Vestweber D: Molecular mechanisms that control leukocyte extravasation: The selectins and the chemokines. Histochem Cell Biol 112: 1-23, 1999.

31. Wang B, Khachigian LM, Esau L, Birrer MJ, Zhao X, Parker MI and Hendricks DT: A key role for early growth response-1 and nuclear factor-kappaB in mediating and maintaining GRO/CXCR2 proliferative signaling in esophageal cancer. Mol Cancer Res 7: 755-764, 2009.

32. Wang D, Yang W, Du J, Devalaraja MN, Liang P, Matsumoto K, Tsubakimoto K, Endo T and Richmond A: MGSA/GRO-mediated melanocyte transformation involves induction of Ras expression. Oncogene 19: 4647-4659, 2000.

33. Belperio JA, Keane MP, Arenberg DA, Addison CL, Ehlert JE, Burdick MD and Strieter RM: CXC chemokines in angiogenesis. J Leukoc Biol 68: 1-8, 2000.

34. Loukinova E, Dong G, Enamorado-Ayalya I, Thomas GR, Chen Z, Schreiber $\mathrm{H}$ and Van Waes C: Growth regulated oncogene-alpha expression by murine squamous cell carcinoma promotes tumor growth, metastasis, leukocyte infiltration and angiogenesis by a host CXC receptor-2 dependent mechanism. Oncogene 19: 3477-3486, 2000.

35. Han L, Liu W, Chen Y, Wu H, Zhang Y and Jiang B: GRO $\alpha$ expression and its prognostic implications in laryngeal squamous cell carcinoma. Neoplasma 62: 152-158, 2015.

36. Doll D, Keller L, Maak M, Boulesteix AL, Siewert JR, Holzmann B and Janssen KP: Differential expression of the chemokines GRO-2, GRO-3, and interleukin-8 in colon cancer and their impact on metastatic disease and survival. Int J Colorectal Dis 25: 573-581, 2010.

37. Dong Q, Zhang J, Hendricks DT and Zhao X: GRO $\beta$ and its downstream effector EGR1 regulate cisplatin-induced apoptosis in WHCO1 cells. Oncol Rep 25: 1031-1037, 2011.

38. Ye Q, Zhai X, Wang W, Zhang S, Zhu H, Wang D and Wang C: Overexpression of growth-related oncogene- $\beta$ Is associated with tumorigenesis, metastasis and poor prognosis in ovarian cancer. Dis Markers 2015: 387382, 2015 